\title{
Muhammad Galib Ishak
}
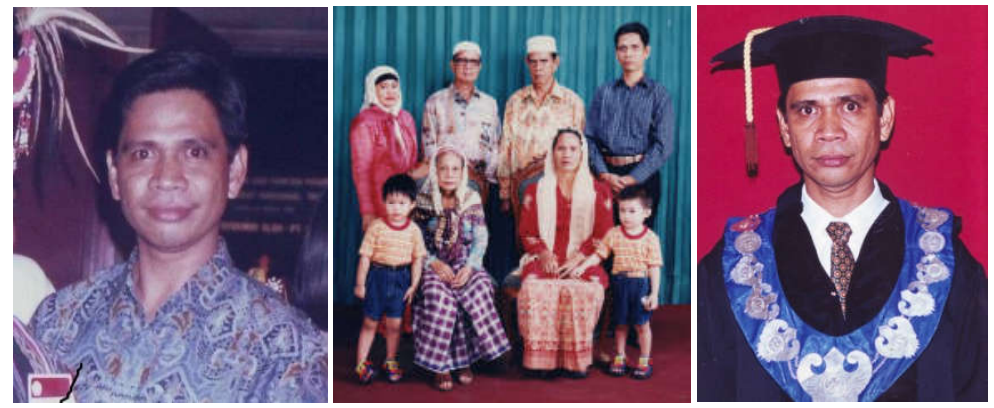

\section{A. Data Pribadi}

Nama

NIP/NIDN

Tempat/Tanggal Lahir

Pangkat/Golongan/ TMT

Jabatan Fungsional Akademik

Alamat Kantor dan No. Telpon

Alamat Rumah/No. HP/E-mail
: Prof. Dr. Ir. H. M. Galib Ishak, MS.

: $195609031985031006 / 0003095605$

: Sengkang(Wajo)/3 September 1956

Pembina Utama Madya/IVd/1 Mei 2018

Profesor/Guru Besar (hydraulics engineer)/1 Mei 2018

Kampus Bumi Tadulako Tondo.

J1. Soekarno-Hatta Km. 9 Tlp. 0451-422844

: JL. Katamso No. 12 Palu

0811452537/galibishak@yahoo.co.id

URL Google Scholar

https://scholar.google.co.id/citations?user $=$ pN2isHQAAAAJ\&hl=en

URL sinta.ristekbrin

http://sinta.ristekbrin.go.id/authors/detail?id=5977230\&view=overview

Nama Istri

Nama Anak

Tanda Tangan
: Dra. Hj. Andi Hadijah Issa

: Nur Abdulrahman dan Nur Abdulrahim

:

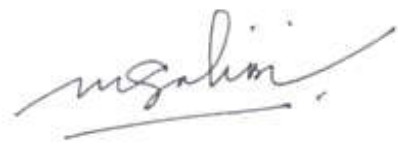

\section{B. Pendidikan}

\begin{tabular}{|c|l|c|}
\hline Jenjang & \multicolumn{1}{|c|}{ Nama Sekolah/Institusi } & $\begin{array}{c}\text { Tahun } \\
\text { Lulus }\end{array}$ \\
\hline SD & SD Negeri Lamasappa Liu Kabupaten Wajo & 1970 \\
\hline SMP & SMP Negeri Salojampu Kabupaten Wajo & 1973 \\
\hline SMA & SMA Negeri IV Makassar, Jurusan IPA & 1976 \\
\hline S1 & S1 Teknik Sipil Universitas Hasanuddin & 1983 \\
\hline S2 & S2 Teknik Sipil/Teknik Sumber Daya Air Institut Teknologi Bandung & 1992 \\
\hline S3 & S3 Teknik Sipil/Teknik Sumber Daya Air Universitas Hasanuddin & 2014 \\
\hline
\end{tabular}




\section{Kepangkatan dan Jabatan Fungsional}

\begin{tabular}{|c|c|c|}
\hline No & Jabatan Fungsional/Pangkat & TMT \\
\hline 1 & Calon Pegawai Negeri Sipil (III/a) & 1 Juni 1985 \\
\hline 2 & $\begin{array}{l}\text { Asisten Ahli Madya } \\
\text { Pegawai Negeri Sipil/ Penata Muda (III/a) }\end{array}$ & 12 Juli 1986 \\
\hline 3 & Asisten Ahli & 1 Mei 1987 \\
\hline 4 & Lektor Muda & 1 Oktober 1989 \\
\hline 5 & Lektor Madya & 30 Maret 1993 \\
\hline 6 & Lektor/ Pembina (IV/a) & 1 September 1995 \\
\hline 7 & Lektor Kepala madya/Lektor Kepala/Pembina TK. I (IV/b) & $\begin{array}{l}\text { 1 Maret } 1998 \\
1 \text { April } 2001\end{array}$ \\
\hline 8 & Lektor kepala/Pembina Utama Muda (IV/c) & 30 Januari 2004 \\
\hline 9 & Profesor/Guru Besar (IV/d) & 1 Mei 2018 \\
\hline
\end{tabular}

\section{Pengalaman Jabatan}

\begin{tabular}{|c|l|c|}
\hline No & \multicolumn{1}{|c|}{ Nama Jabatan } & \multicolumn{1}{|c|}{$\begin{array}{c}\text { Priode } \\
\text { Tahun }\end{array}$} \\
\hline 1 & Sekretaris Senat Fakultas Teknik Untad & $1993-1994$ \\
\hline 2 & Ketua Jurusan Teknik Sipil Fak. Teknik Untad & $1993-1995$ \\
\hline 3 & Wakil Direktur Bidang Civil Work ADB Loan No. 1253 Ino Untad & $1994-1996$ \\
\hline 4 & Direktur ADB Loan No. 1253 Ino Universitas Tadulako & $1996-2000$ \\
\hline 5 & Dekan Fakultas Teknik Universitas Tadulako (Priode I dan II) & $1999-2003$ \\
& & $2003-2007$ \\
\hline 6 & Ketua Lembaga Penelitian Universitas Tadulako & $2009-2011$ \\
\hline 7 & Anggota dan Sekretaris Dewan Pertimbangan Universitas Tadulako & $2011-2015$ \\
\hline 8 & Anggota Satuan Pengawas Internal (SPI) Universitas Tadulako & $2016-2017$ \\
\hline 9 & Ketua Komisi Etik UniversitasTadulako & $2018-$ \\
\hline
\end{tabular}

\section{E. Penghargaan/Piagam}

\begin{tabular}{|c|l|l|}
\hline Tahun & \multicolumn{1}{|c|}{ Bentuk Penghargaan } & \multicolumn{1}{c|}{ Pemberi } \\
\hline 1995 & Dosen Teladan Nasional (50 Tahun Indonesia) & Menteri Pendidikan dan Kebudayaan R.I \\
\hline 2003 & Penghargaan Satyalencana Karya Satya X & Pemerintah R. I \\
\hline 2011 & Penghargaan Satyalencana Karya Satya XX & Pemerintah R. I \\
\hline
\end{tabular}

\section{H. Pengalaman Profesional}

\begin{tabular}{|r|l|c|}
\hline No & \multicolumn{1}{|c|}{ Kegiatan } & Tahun \\
\hline 1 & Supervisor pada In-Situ Constructioan Road PLTA Bakaru Propinsi Sulawesi Selatan & $1982-1984$ \\
\hline 2 & Site Manager Proyek Daerah Irigasi Parigi Kanan (Proyek PIGPP) & $1984-1985$ \\
\hline 3 & Site Manager Proyek Rumah Sakit Toli-toli (IFAD) & $1985-1986$ \\
\hline
\end{tabular}




\begin{tabular}{|r|l|c|}
\hline 4 & Site Manager Proyek Pembangunan Jembatan Palu III & $1986-1987$ \\
\hline 5 & Site Manager Proyek Jalan dan Jembatan di Mengsong - Kota Raya - Tinombala & $1987-1988$ \\
\hline 6 & Site Manager Pengaspalan Kota Palu (Lapis HRS) & $1988-1989$ \\
\hline 7 & Perencana Rangka Baja Pembangunan Aula Pertanian di Biromaru & 1990 \\
\hline 9 & Site Engineer Proyek Rehabilitasi Daerah Irigasi Pesisir Barat Danau Poso & 1993 \\
\hline
\end{tabular}

\section{Organisasi Profesi}

\begin{tabular}{|c|l|l|}
\hline Tahun & \multicolumn{1}{|c|}{ Nama Organisasi } & \multicolumn{1}{|c|}{ Posisi } \\
\hline $1999-2003$ & LPJK Propinsi Sulawesi Tengah & $\begin{array}{l}\text { Wakil Ketua Bidang Profesi } \\
\text { dan Diklat }\end{array}$ \\
\hline $2010-2014$ & PII DPW Sulawesi Tengah & Wakil Ketua \\
\hline $1995-1999$ & DPP Inkindo Propinsi Sulawesi Tengah & Pengurus \\
\hline $\begin{array}{c}2010- \\
\text { sekarang }\end{array}$ & DPW HATHI Cabang Palu Propinsi Sulawesi Tengah & $\begin{array}{l}\text { Ketua Komisi Hub Masyarakat } \\
\text { dan Setifikasi }\end{array}$ \\
\hline $\begin{array}{c}2011- \\
\text { sekarang }\end{array}$ & $\begin{array}{l}\text { DPD Asosiasi Tenaga Teknik Indonesia Propinsi Sulawesi } \\
\text { Tengah }\end{array}$ & Anggota Dewan Pertimbangan \\
\hline
\end{tabular}

\section{J. Kepanitiaan dalam Lingkungan Universitas Tadulako}

\begin{tabular}{|c|l|c|}
\hline No & \multicolumn{1}{|c|}{ Kegiatan } & Tahun \\
\hline 1 & $\begin{array}{l}\text { Wakil Ketua Bidang Buku III Rencana Induk Pengembangan II (RIP II) Untad, tahun } \\
1992-2002\end{array}$ & 1992 \\
\hline 2 & Ketua Penyusun Usulan ADB Loan no. 1253 Ino HEP Untad 1993 & 1993 \\
\hline 3 & Ketua Penyusun Usulan ADB Loan No. 1452 Ino EEDP Untad 1994 & 1994 \\
\hline 4 & Ketua Perencanaan Master Plan Untad (tahun 2007-2017) & 2007 \\
\hline 5 & Ketua Kelompok II (Organisasi) Penyusun Statuta Untad (bidang organisasi) & 2008 \\
\hline 6 & Anggota Penyusun Renstra Untad & 1998 \\
\hline 7 & Ketua Tim Revisi Master Plan Untad (2011-2017) & 2010 \\
\hline 8 & Ketua Tim Penyusun Organisasi Tata Kerja (OTK) Untad tahun 2011 & 2011 \\
\hline 9 & Ketua Tim Penyelenggara Optimalisasi Jaringan Air Bersih Kampus Untad-Tondo Tahun & 2012 \\
\hline 10 & Anggota Tim Perumusan Remunerasi & 2016 \\
\hline 11 & Ketua Tim Perancang Rencana Induk Pengembangan (RIP) 2015-2045 & 2015 \\
\hline
\end{tabular}

